\title{
Individual and social determinants of multiple chronic disease behavioral risk factors among youth
}

\author{
Arsham Alamian ${ }^{1 *}$ and Gilles Paradis ${ }^{2,3}$
}

\begin{abstract}
Background: Behavioral risk factors are known to co-occur among youth, and to increase risks of chronic diseases morbidity and mortality later in life. However, little is known about determinants of multiple chronic disease behavioral risk factors, particularly among youth. Previous studies have been cross-sectional and carried out without a sound theoretical framework.

Methods: Using longitudinal data $(n=1135)$ from Cycle 4 (2000-2001), Cycle 5 (2002-2003) and Cycle 6 (20042005) of the National Longitudinal Survey of Children and Youth, a nationally representative sample of Canadian children who are followed biennially, the present study examines the influence of a set of conceptually-related individual/social distal variables (variables situated at an intermediate distance from behaviors), and individual/social ultimate variables (variables situated at an utmost distance from behaviors) on the rate of occurrence of multiple behavioral risk factors (physical inactivity, sedentary behavior, tobacco smoking, alcohol drinking, and high body mass index) in a sample of children aged 10-11 years at baseline. Multiple behavioral risk factors were assessed using a multiple risk factor score. All statistical analyses were performed using SAS, version 9.1, and SUDAAN, version 9.01 .
\end{abstract}

Results: Multivariate longitudinal Poisson models showed that social distal variables including parental/peer smoking and peer drinking (Log-likelihood ratio $(L L R)=187.86$, degrees of freedom $(D F)=8, p<.001$ ), as well as individual distal variables including low self-esteem $(L L R=76.94$, $D F=4, p<.001)$ increased the rate of occurrence of multiple behavioral risk factors. Individual ultimate variables including age, sex, and anxiety (LLR $=9.34, D F=3$, $p<.05)$, as well as social ultimate variables including family socioeconomic status, and family structure (LLR $=$ $10.93, \mathrm{DF}=5, p=.05$ ) contributed minimally to the rate of co-occurrence of behavioral risk factors.

Conclusions: The results suggest targeting individual/social distal variables in prevention programs of multiple chronic disease behavioral risk factors among youth.

\section{Background}

Chronic (long-lasting) diseases including heart disease, stroke, cancer and diabetes are by far the leading causes of death worldwide [1]. Behavioral risk factors including tobacco smoking, alcohol drinking, physical inactivity, sedentary behavior, and obesity are major determinants of adult chronic diseases morbidity and mortality $[2,3]$. For instance, nearly $80 \%$ of incident cases of cardiovascular disease and type 2 diabetes are attributable to

\footnotetext{
* Correspondence: alamian@etsu.edu

'Department of Biostatistics and Epidemiology, College of Public Health, East Tennessee State University, Johnson City, Tennessee, USA

Full list of author information is available at the end of the article
}

physical inactivity, tobacco smoking and unhealthy diet alone [1]. About $35 \%$ of all cancers are also preventable by reducing or avoiding exposure to risk factors such as tobacco use, physical inactivity, poor diet, alcohol use or being overweight or obese [4].

Chronic disease behavioral risk factors originate in childhood and adolescence [5-9], and cause significant negative health and social consequences throughout the life course $[2,10,11]$. In particular, physically inactivity has been linked to an unfavorable cardiovascular disease risk profile including obesity [12], insulin resistance [10], and high blood pressure [13]. Sedentary behavior has been associated with being overweight as it involves a

\section{Ciomed Central}


decrease in energy expenditure and an increase in energy intake through consumption of high-fat and lownutrient foods [14]. Smoking at a young age has been associated with emotional and psychological problems, engaging in risky behaviors such as violence and sexual activity, and an increased risk for lung cancer later in life $[15,16]$. Underage alcohol drinking has been suggested to increase rates of suicide and homicide, and even death from alcohol poisoning [17]. Lastly, obesity during childhood has been linked to increased risk of dyslipidemia, hyperinsulinemia, hypertension, and a number of psychosocial problems $[18,19]$.

In addition to the burden of disease attributed to single chronic behavioral risk factors, a growing body of evidence also suggests that behavioral risk factors (including physical inactivity, sedentary behavior, smoking, alcohol use, and obesity) co-occur among youth [20-23], and that their combinations yield greater risks for chronic diseases than the sum of their individual independent effects [24]. Although much is known about single behavioral risk factors and their determinants, less is known about potential determinants of multiple behavioral risk factors, particularly among youth. Previous studies of multiple behavioral risk factors for chronic diseases have been cross-sectional; these studies have identified a limited number of individual characteristics, such as being female $[22,25]$, older age [25-27], depression [26,28] and low self-esteem [27], as well as social characteristics, including living in a lone-parent family [26,27], low parental education [27] and parental unhealthy lifestyles [25,27] as correlates of multiple behavioral risk factors among youth. While these findings are important, there is a need for longitudinal studies to obtain more conclusive evidence for planning cost-effective interventions.

Identifying factors that contribute to the co-occurrence of health behaviors should be based on a theory applicable to multiple behaviors [29]. However, previous studies of multiple behavioral risk factors have not consistently used a sound theoretical framework $[22,25,28,30]$. In addition, several theories of health behavior, including the Health Belief Model [31], the Theory of Reasoned Action [32] and the Theory of Planned Behavior [33] are considered behavior-specific, because these theories suggest that each behavior has its own set of determinants, commonly referred to as proximal factors (i.e., the most immediate determinants of specific behaviors) [34,35]; these include attitudinal, social normative beliefs, self-efficacy and decisional/ intentional factors [29].

Other prominent theories including the Social Learning Theory [36], the Problem Behavior Theory [37], the Bronfenbrenner's Ecological Systems Theory [38], and the Theory of Triadic Influence [39] address more distal determinants of behaviors such as self-esteem, social bonding with others as well as characteristics of the social environment. However, of all integrative theories, the Theory of Triadic Influence seems to be the most comprehensive as it proposes a framework for mapping out the relationships between determinants of different types (including individual and social characteristics) and the occurrence of both single and multiple behaviors $[34,39]$. According to the Theory of Triadic Influence, individual and social factors influence health behaviors through 3 tiers of constructs, represented by several proximal, distal and ultimate variables. Flay and Petraitis [39] argue that as opposed to proximal variables which are behavior-specific, distal and ultimate variables are likely to have more generalizable effects and thus, they are thought to be predictive of multiple behaviors [35]. In particular, ultimate variables are the most general set of principles that transcend specific behaviors, and they comprise factors considered almost unchangeable such as inherited dispositions (e.g., sex, age), or factors that are difficult to change such as personality traits (e.g., anxiety) and characteristics of the social environment (e.g. family socioeconomic status) [39]. Hence, ultimate variables are considered to be furthest from behavior(s), in terms of distance, and believed to be not specific to a single behavior. As a result, ultimate variables are hypothesized to strongly influence multiple behaviors. Distal variables are more immediate determinants of behavior(s) (compared to ultimate variables), and they comprise factors considered easier to modify, such as one's general knowledge, social relations and sense of self [39]. Distal variables are also hypothesized to influence multiple behaviors, but to a lesser degree compared to ultimate variables, since they are closer to behavior(s) (i.e., they are assumed to exert less generalized effects across behaviors).

To our knowledge, no study has yet investigated the longitudinal relation between a large set of distal and ultimate variables and the occurrence of multiple behavioral risk factors for chronic diseases among youth. The present study is therefore guided by the Theory of Triadic Influence and uses longitudinal data to examine the influence of selected individual/social distal and ultimate variables on the rate of occurrence of multiple behavioral risk factors in a representative sample of Canadian youth. We hypothesized that both distal and ultimate variables would influence the rate of co-occurrence of chronic disease behavioral risk factors among youth. However, ultimate determinants would be expected to exert a stronger influence on the rate of occurrence of multiple chronic disease behavioral risk factors, compared to distal determinants, due to their potentially broader effects. 


\section{Methods}

\section{Study population}

The National Longitudinal Survey of Children and Youth (NLSCY) is a large representative survey of Canadian children and adolescents that follows their development and well-being from birth to adulthood. The NLSCY uses a stratified, multistage probability sample design with data collection occurring at two-year intervals [40]. The present analysis was based on a weighted longitudinal sample of Canadian children aged 10-11 years in Cycle 4 (2000-2001), 12-13 years in Cycle 5 (2002-2003) and 14-15 years in Cycle 6 (2004-2005) of the NLSCY. Of 2081 children aged 10-11 years in Cycle 4, 1838 (88.3\%) responded to Cycle 5. Of these 1838 youth, 1649 (79.2\% of the original sample) responded to Cycle 6. Of these 1649 youth, analyses were based on 1135 youth $(68.9 \%)$ with complete data on lifestyle variables and covariates. Table 1 presents the baseline characteristics of children included in the study population and of those lost to follow-up or excluded because of incomplete data. This study received approval from the Ethics Committee on Research on Human Subjects of the Faculty of Medicine of the University of Montreal.

\section{Data collection}

The person most knowledgeable (PMK) about the child, most often the mother, completed a parent questionnaire and a child questionnaire. The parent questionnaire gathered information on family socioeconomic status and PMK adverse health behaviors, while the child questionnaire was used to obtain the child's height and weight (for children below age 12 years). Specifically, the PMK was asked to indicate the child's height in meters and centimetres, and to report the child's weight in kilograms and grams. Adolescents aged 12 years or more self-reported their height and weight. Information regarding youth behaviors and social relations was assessed through age-specific self-administered questionnaires for children aged 10 years or more.

\section{Measures}

\section{Risk factors}

Physical inactivity was measured in Cycles 4, 5 and 6 using 2 closed questions adapted from the World Health Organization Health Behavior in School-aged Children (HBSC) survey: 1) "During the past 12 months, how often have you played sports or done physical activities without a coach or an instructor (biking, skateboarding, etc.)?"; 2) "During the past 12 months, how often have you played sports with a coach or an instructor, other than gym class (swimming lessons, baseball, hockey, etc.)?" [41]. Response choices included "never", "less than once a week", "1 to 3 times a week" and " 4 or more times a week". Because the Canadian Physical activity Guides for Children and Youth [42] recommend daily participation in physical activities, we defined physical inactivity as engaging in organized/unorganized activities fewer than 4 times per week. The physical activity questions have been validated by means of the Multistage Fitness Test [43], and have been shown to have acceptable validity. The intra-class correlation coefficient for the reliability of this measure was 0.74 , in the targeted age groups [44].

Sedentary behavior was measured in Cycles 4, 5 and 6 using a closed question from the HBSC survey: "On average, about how many hours a day do you watch television or videos?" [41]. Because the American Academy of Pediatrics guidelines recommend limiting screen viewing to 2 hours per day or less [45], we defined sedentary behavior as watching television or videos for more than 2 hours per day. The sedentary behavior measure has been validated using a 7-day television viewing diary. Spearman correlation coefficients ranged from 0.36 to 0.54 [46]. Test-retest intra-class correlation scores for the reliability of this measure ranged from 0.76 to $0.81[41,46]$.

Cigarette smoking was assessed using a closed question adapted from the HBSC survey asking youth about their past experience with tobacco smoking [41]. Previous research has indicated that any cigarette use places the child at greater risk for subsequent use and children who begin smoking at an early age are more likely to develop severe nicotine addiction than those who start later $[47,48]$. Thus, we used Health Canada's definition of ever smoking, that is, having ever tried a cigarette, even a few puffs [49], in Cycles 4, 5 and 6.

Alcohol drinking was assessed using two closed questions inquiring about past experience with alcohol consumption $[41,50]$. Longitudinal studies have shown that children who start drinking (more than just a few sips) as early as 11 years of age are at increased risk of becoming problem and heavy drinkers later in life $[51,52]$. Thus, we defined alcohol drinking as ever drinking, that is ever having had at least 1 alcoholic drink, as suggested by others [53], in Cycles 4, 5 and 6 .

High body mass index (weight $(\mathrm{kg}) /$ height $(\mathrm{m})^{2}$ ) was defined as overweight or obese, in all three cycles, according to Cole and colleagues' [54] international ageand sex-specific body mass index cutoffs for children and adolescents, corresponding to body mass indices of 25 and 30, respectively, at age 18 years.

\section{Independent variables}

The independent variables were selected on the basis of factors previously identified as correlates of several lifestyle risk factors in the literature and comprised four blocks of variables: individual ultimate, individual distal, social ultimate and social distal variables, as per our conceptual framework based on the Theory of Triadic Influence (Figure 1). 
Table 1 Comparison of baseline characteristics of children in the study cohort and of subjects lost to follow-up or excluded because of incomplete data, National Longitudinal Survey of Children and Youth, 2000-2005

\begin{tabular}{|c|c|c|c|}
\hline & Study cohort, $\%^{a}$ & Subjects lost, $\%^{\mathrm{a}}$ & $p$ value $^{b}$ \\
\hline & $(n=1135)$ & $(n=946)$ & \\
\hline \multicolumn{4}{|l|}{ Individual characteristics } \\
\hline \multicolumn{4}{|l|}{ Ultimate } \\
\hline Sex & & & .03 \\
\hline Female & 51 & 46 & \\
\hline Age, years & & & .26 \\
\hline 10 & 50 & 53 & \\
\hline 11 & 50 & 47 & \\
\hline Anxiety, mean (SE) ${ }^{c}$ & $3.4(0.1)$ & $3.7(0.1)$ & .02 \\
\hline \multicolumn{4}{|l|}{ Distal } \\
\hline Self-esteem, mean (SE) ${ }^{d}$ & $13.7(0.1)$ & $13.3(0.1)$ & $<.001$ \\
\hline Academic performance & & & .56 \\
\hline Poor/very poor & 2 & 1 & \\
\hline Average & 18 & 19 & \\
\hline Well & 46 & 46 & \\
\hline Very well & 34 & 34 & \\
\hline \multicolumn{4}{|l|}{ Social characteristics } \\
\hline \multicolumn{4}{|l|}{ Ultimate } \\
\hline Family structure & & & .005 \\
\hline 2 parents & 84 & 79 & \\
\hline 1 parent & 16 & 21 & \\
\hline PMK Education & & & $<.001$ \\
\hline Low (< 12 years of school) & 19 & 28 & \\
\hline High ( $\geq 12$ years of school) & 81 & 73 & \\
\hline Annual household income, CAN \$ & & & $<.001$ \\
\hline$<30,000$ & 15 & 21 & \\
\hline $30,000-59,999$ & 31 & 40 & \\
\hline $60,000-89,999$ & 31 & 23 & \\
\hline$\geq 90,000$ & 23 & 16 & \\
\hline \multicolumn{4}{|l|}{ Distal } \\
\hline PMK smoking status & & & .03 \\
\hline Tobacco smoker & 26 & 30 & \\
\hline PMK drinking status & & & .61 \\
\hline Alcohol drinker & 28 & 27 & \\
\hline Parent-child relationship, mean (SE) ${ }^{e}$ & $22.9(0.2)$ & $22.3(0.2)$ & .005 \\
\hline Peer smoking & & & .94 \\
\hline No peers & 95 & 96 & \\
\hline A few peers & 4 & 3 & \\
\hline Most/all peers & 1 & 1 & \\
\hline Peer drinking & & & .05 \\
\hline No peers & 97 & 95 & \\
\hline A few peers & 2 & 4 & \\
\hline Most/all peers & 1 & 1 & \\
\hline Peer-child relationship, mean $(\mathrm{SE})^{f}$ & $12.8(0.1)$ & $12.8(0.1)$ & .86 \\
\hline \multicolumn{4}{|l|}{ Lifestyle risk factors } \\
\hline Physical inactivity ${ }^{g}$ & 50 & 54 & .09 \\
\hline
\end{tabular}


Table 1 Comparison of baseline characteristics of children in the study cohort and of subjects lost to follow-up or excluded because of incomplete data, National Longitudinal Survey of Children and Youth, 2000-2005 (Continued)

\begin{tabular}{|c|c|c|c|}
\hline Sedentary behavior ${ }^{\text {h }}$ & 42 & 46 & .11 \\
\hline Ever smoking ${ }^{i}$ & 6 & 7 & .60 \\
\hline Ever drinking $^{j}$ & 6 & 10 & .005 \\
\hline High body mass index ${ }^{k}$ & 23 & 29 & .004 \\
\hline
\end{tabular}

CAN = Canadian; PMK = person most knowledgeable; SE = standard error.

${ }^{\text {a }}$ Weighted percentage expressed in terms of the proportion of Canadian children aged 10-11 years in Cycle 4 and followed biennially until Cycle 6 of the

National Longitudinal Survey of Children and Youth.

${ }^{b} p$ value from a chi-squared test or $t$ test.

c Anxiety was assessed using a global score ranging from 0 to 14 , with higher scores indicating the presence of greater anxiety.

d Self-esteem was assessed using a global score ranging from 0 to 16 , with higher scores indicating positive self-esteem.

e The parent-child relationship was assessed using a global score ranging from 0 to 28 , with higher scores indicating a better relationship between parents and child.

${ }^{f}$ Peer-child relationships were assessed using a global score ranging from 0 to 16 , with higher scores indicating a better relationship between the child and his/ her peers.

${ }^{g}$ Engaging in organized/unorganized physical activities fewer than 4 times per week.

${ }^{\mathrm{h}}$ Watching television or videos for more than 2 hours per day.

'Ever smoking a cigarette, even a few puffs.

${ }^{j}$ Ever having a standard drink of alcohol.

${ }^{k}$ Being overweight/obese, as defined by cutoff points of Cole and colleagues [54].

Individual ultimate variables referred to demographic and personality factors such as sex, age at baseline (1011 years in Cycle 4), and anxiety. Anxiety was assessed, in Cycles 4 through 6, using 7 questions from the Ontario Child Health Study assessing degree of nervousness, anxiety and depression [55]. Based on the responses, a global score ranging from 0 to 14 was calculated, with higher scores indicating the presence of greater anxiety. This measure has been validated through factor analyses and has been shown to have good construct validity. Its reliability was also satisfactory (Cronbach's $\alpha=0.76$ ) in the NLSCY [50].
Individual distal variables referred to child's sense of self and achievement such as self-esteem and academic performance. Self-esteem was measured, in Cycles 4 through 6, using 4 items from the General Self-Scale of the Marsh Self-Description Questionnaire [56]. A global score ranging from 0 to 16 was computed, with higher scores indicating positive self-esteem. This measure has been shown to have high convergent validity (factor intercorrelation $=0.76$ ) [57]. Its reliability was also satisfactory (Cronbach's $\alpha=0.73$ ) in the NLSCY [50]. Academic performance was assessed, in Cycles 4 through 6, using a closed question: "How well do you think you are

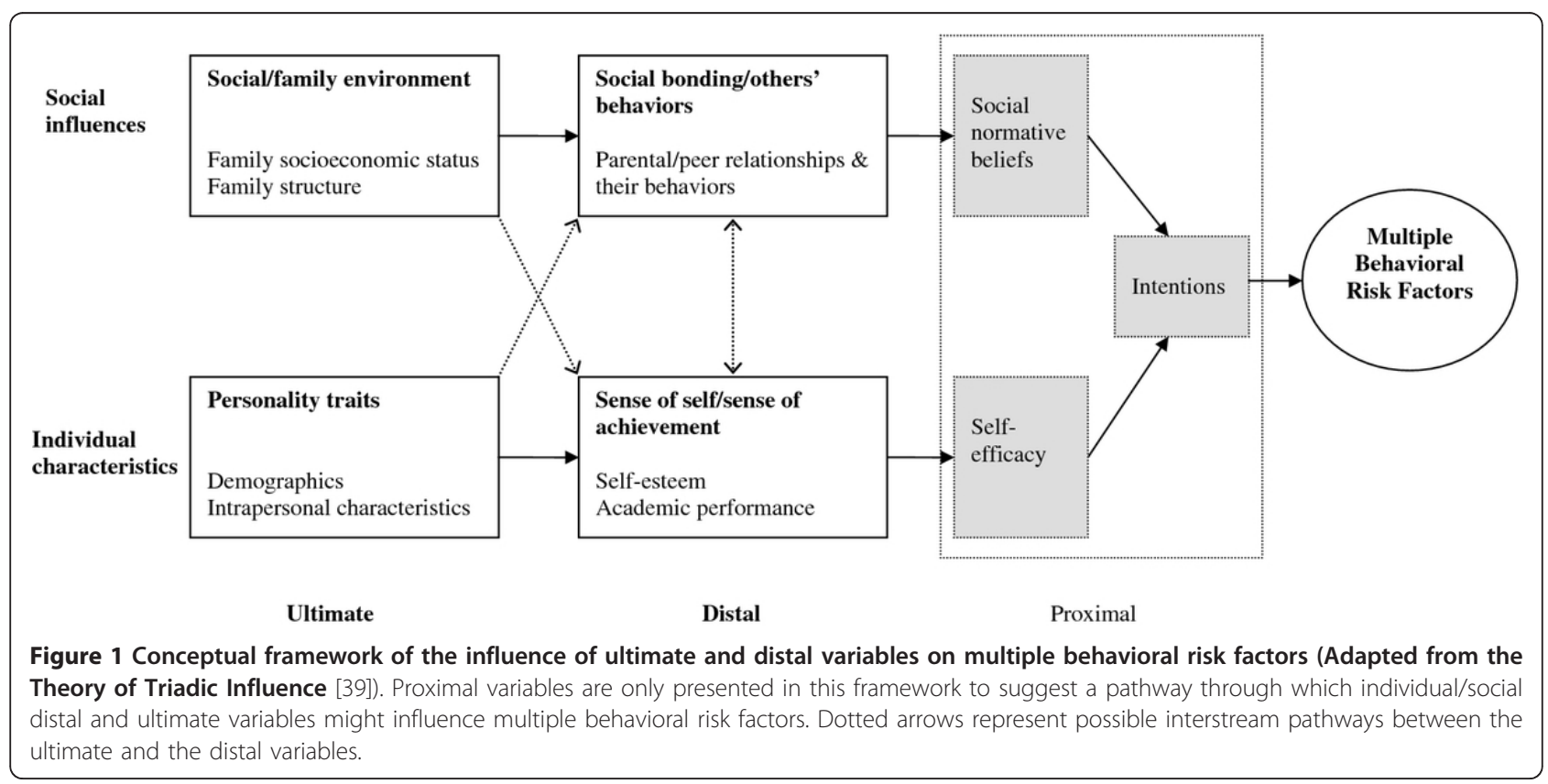


doing in your school work?" [50]. Response choices included: "very well", "well", "average", "poor" and "very poor". In the analyses, the response categories "poor" and "very poor" were combined to ensure adequate cell sizes.

Social ultimate variables referred to characteristics of the child's immediate social environment such as family structure (2 parents, 1 parent); PMK education defined as low education (< 12 years of schooling) and high education (12 years of schooling or more) [58,59]; and total annual household income $(<\mathrm{Can} \$ 30,000$, Can\$30,00059,999, Can\$60,000-89,999 or $\geq$ Can\$90,000) [60], assessed in all cycles.

Social distal variables pertained to child's social relations with others as well as behaviors of influential role models. PMK smoking was defined as smoking "daily" or "occasionally", in all cycles [50]. PMK drinking was defined as consuming alcohol at least once a week or more, in all cycles $[50,61]$. The parent-child relationship was assessed, in Cycles 4 through 6, using 7 questions from the Western Australia Child Health Survey evaluating the child's perception of the parents' degree of attention, appreciation and affection [50]. A global score ranging from 0 to 28 was computed, with higher scores indicating better parent-child relationships. The reliability of this scale was excellent (Cronbach's $\alpha=0.88$ ) in the NLSCY [50]. Peer smoking and peer drinking were assessed, in Cycles 4 through 6, using 2 closed questions: "How many of your close friends smoke cigarettes"? and "How many of your close friends drink alcohol?" [50]. Response choices included "none", "a few", "most" and "all". In the analyses, response categories "most" and "all" were combined to ensure adequate cell sizes. Peer-child relationships were assessed, in Cycles 4 through 6, using 4 items from the Ontario Child Health Study evaluating how well the child feels he/she gets along with his/her peers [55]. A global score ranging from 0 to 16 was computed, with higher scores indicating better relationships with peers. The reliability of this scale was satisfactory (Cronbach's $\alpha=0.78$ ) in the NLSCY [50].

\section{Statistical analyses}

Baseline characteristics of the study cohort were described using the chi-squared test and t-test. The prevalence and 95\% confidence intervals (CIs) of single and multiple behavioral risk factors by sex were estimated using sampling and bootstrap weights [40]. Single behavioral risk factors were coded as binary variables (yes = 1 , no $=0)$. A multiple risk factor score ranging from 0 to $5(0=$ no risk factors, $5=$ all 5 risk factors $)$ was then created by summing individual risk factor scores [25]. Sex-specific trends in the percentage of single and multiple behavioral risk factors were examined using polynomial trend tests [62]. We used longitudinal Poisson regression, within a generalized estimating equations (GEE) framework, to assess the longitudinal associations between selected individual/social distal and ultimate variables and the multiple risk factor score. GEE models account for non-independence of repeated observations and provide robust parameter and standard error estimates [63]. In addition, the longitudinal Poisson regression models provided direct estimates of rate ratios for the associations between selected covariates and the multiple risk factor score along the entire follow-up period [64]. First, a set of longitudinal Poisson models was constructed to assess the direct influence of individual ultimate and individual distal variables on the rate of multiple risk factor score. We then built a second set of longitudinal Poisson models to assess the direct influence of social ultimate and social distal variables on the rate of multiple risk factor score. A final set of four multivariate models was then constructed to assess the independent longitudinal influence of individual distal/ ultimate and social distal/ultimate variables on the rate of multiple risk factor score. Specifically, Model 1 assessed the contribution of individual distal variables; Model 2 assessed the contribution of individual ultimate variables controlling for the effects of individual distal variables; Model 3 assessed the contribution of social distal variables controlling for the effects of individual distal and individual ultimate variables; and Model 4 assessed the contribution of social ultimate variables controlling for the effects of social distal, individual distal, and individual ultimate variables (i.e., all covariates). The log-likelihood ratio statistic was used to assess the contribution of each block of variables to the models [64]. Interaction terms were added to the models to test possible interactions between each covariate and sex as well as between each covariate and time. Sampling and bootstrap weights were used in all analyses to adjust for sample selection and non-response [40]. All statistical analyses were performed using SAS, version 9.1 (SAS Institute Inc., Carry, NC), and SUDAAN, version 9.01 (RTI International, Research Triangle Park, NC).

\section{Results}

\section{Descriptive findings}

Analyses comparing baseline characteristics of children in the study cohort to those of subjects lost during the follow-up or excluded because of incomplete data showed that subjects lost were more often males ( $p=$ $.03)$, had lower self-esteem $(p<.001)$ and greater anxiety $(p=.02)$ (Table 1$)$. Subjects lost were also more likely to be from lower socioeconomic status families than children in the study cohort. With respect to lifestyle risk factors, there were no significant differences between the two groups except for ever drinking $(p=.005)$ and 
high body mass index $(p=.004)$, which were higher among subjects who were lost to follow-up or excluded from the analysis.

At baseline (2000-2001), 50\% of children in the study cohort, aged 10-11 years, were physically inactive, $42 \%$ engaged in sedentary behavior, $6 \%$ were ever smokers, $6 \%$ were ever drinkers and $23 \%$ were overweight or obese (Table 2). For males and females, respectively, the prevalence of physical inactivity increased by $18 \%(p<$ $.001)$ and $15 \%(p=.002)$, the prevalence of ever smoking increased by $25 \%(p<.001)$ and $23 \%(p<.001)$ and the prevalence of ever drinking increased by $41 \%(p<$ $.001)$ and $43 \%(p<.001)$ from 2000-2001 to 2004-2005.
Overall, females were more physically inactive than males $(p<.02)$, while males tended to engage in more sedentary behavior than females especially at the age of 14-15 years $(p=.002)$.

About $28 \%$ of children at baseline aged 10-11 years had none of the five behavioral risk factors, $41 \%$ had 1 risk factor, $24 \%$ had 2 risk factors and $7 \%$ had 3 or more risk factors (Table 2). By the age of 14-15 years, only $8 \%$ of these youth had no risk factors, $29 \%$ had 1 risk factor, $32 \%$ had 2 risk factors and 31\% had 3 risk factors or more. There were no significant differences between males and females in the percentage of multiple behavioral risk factors at baseline or across the follow-up period.

Table 2 Prevalence of single and multiple behavioral risk factors, by sex, at each time point, National Longitudinal Survey of Children and Youth, 2000-2005

\begin{tabular}{|c|c|c|c|c|c|c|c|c|}
\hline & & \multirow{2}{*}{\multicolumn{2}{|c|}{$\begin{array}{c}\text { Time } 1^{a} \\
(n=1135)\end{array}$}} & \multirow{2}{*}{\multicolumn{2}{|c|}{$\begin{array}{c}{\text { Time } 2^{\mathrm{a}}}_{(\mathrm{n}=1135)} \\
\end{array}$}} & \multicolumn{2}{|c|}{ Time $3^{a}$} & \multirow{3}{*}{$\frac{p}{\text { for trend }}$} \\
\hline & & & & & & & 1135) & \\
\hline & & $\%^{\mathbf{b}}$ & $95 \% \mathrm{Cl}^{\mathrm{C}}$ & $\%^{\mathbf{b}}$ & $95 \% \mathrm{Cl}^{\mathrm{c}}$ & $\%^{\mathbf{b}}$ & $95 \% \mathrm{Cl}^{\mathrm{C}}$ & \\
\hline \multicolumn{9}{|l|}{ Risk factors } \\
\hline \multirow[t]{2}{*}{ Physical inactivity $^{\mathrm{e}}$} & Male & 43 & 36,49 & 44 & 37,50 & 61 & 55,67 & $<.001$ \\
\hline & Female & 57 & 50,64 & 59 & 52,65 & 72 & 65,78 & .002 \\
\hline \multirow[t]{2}{*}{ Sedentary behavior ${ }^{f}$} & Male & 49 & 42,55 & 43 & 37,50 & 50 & 44,56 & .78 \\
\hline & Female & 36 & 30,42 & 36 & 30,43 & 36 & 29,42 & .99 \\
\hline \multirow[t]{2}{*}{ Ever smoking $^{9}$} & Male & 6 & 3,11 & 12 & 9,17 & 31 & 26,38 & $<.001$ \\
\hline & Female & 6 & 3,10 & 15 & 11,20 & 29 & 24,36 & $<.001$ \\
\hline \multirow[t]{2}{*}{ Ever drinking $^{\mathrm{h}}$} & Male & 7 & 4,11 & 16 & 12,22 & 48 & 41,54 & $<.001$ \\
\hline & Female & 5 & 3,9 & 14 & 10,18 & 48 & 41,55 & $<.001$ \\
\hline \multirow[t]{2}{*}{ High body mass index } & Male & 24 & 19,30 & 23 & 17,30 & 18 & 13,23 & .07 \\
\hline & Female & 22 & 17,29 & 15 & 11,19 & 14 & 10,18 & .05 \\
\hline \multicolumn{9}{|l|}{ No. of Risk factors } \\
\hline \multirow[t]{2}{*}{0} & Male & 31 & 25,37 & 21 & 17,26 & 6 & 4,11 & $<.001$ \\
\hline & Female & 26 & 21,32 & 22 & 17,28 & 10 & 6,16 & $<.001$ \\
\hline \multirow[t]{2}{*}{1} & Male & 38 & 32,44 & 40 & 34,47 & 27 & 22,32 & .003 \\
\hline & Female & 44 & 37,50 & 39 & 33,47 & 31 & 24,38 & .01 \\
\hline \multirow[t]{2}{*}{2} & Male & 24 & 19,30 & 27 & 22,33 & 37 & 31,43 & .002 \\
\hline & Female & 24 & 19,29 & 25 & 18,32 & 27 & 21,34 & .42 \\
\hline \multirow[t]{2}{*}{$3-5$} & Male & 7 & 5,11 & 12 & 8,16 & 30 & 25,36 & $<.001$ \\
\hline & Female & 6 & 4,11 & 14 & 10,19 & 32 & 27,38 & $<.001$ \\
\hline
\end{tabular}

$\mathrm{Cl}=$ confidence interval.

a Time 1 refers to Cycle 4 (2000-2001), Time 2 refers to Cycle 5 (2002-2003) and Time 3 refers to Cycle 6 (2004-2005) of the National Longitudinal Survey of Children and Youth.

${ }^{b}$ Weighted percentage expressed in terms of the proportion of Canadian children aged 10-11 years in Cycle 4 and followed biennially until Cycle 6 of the National Longitudinal Survey of Children and Youth.

' Cls were computed using bootstrap weights to account for the complex sampling design of the National Longitudinal Survey of Children and Youth.

${ }^{d} p$ value for linear trend in the percentages of single and multiple behavioral risk factors over time obtained from the polynomial trend test.

e Engaging in organized/unorganized physical activities fewer than 4 times per week.

${ }^{\mathrm{f}}$ Watching television or videos for more than 2 hours per day.

${ }^{g}$ Ever smoking a cigarette, even a few puffs.

h Ever having a standard drink of alcohol.

' Being overweight/obese, as defined by cutoff points of Cole and colleagues [54]. 


\section{Longitudinal Poisson regression models}

In the regression analyses, individual and social variables were grouped into 4 blocks of conceptually-related variables (as per our conceptual framework) to determine their influence on the rate of multiple risk factor score. Longitudinal Poisson models assessing the direct influence of individual distal and individual ultimate variables on the rate of multiple risk factor score showed that both individual distal and individual ultimate variables contributed to the model (Table 3). However, individual distal variables (Table 3, Model 2, Log-likelihood ratio $($ LLR) $=76.94$; degrees of freedom $(\mathrm{DF})=4 ; p<.001)$ contributed more to the model than individual ultimate variables (Table 3 , Model 1, LLR $=35.9 ; \mathrm{DF}=3 ; p<.001$ ).

Analyses assessing the direct influence of social distal and social ultimate variables on the rate of multiple risk factor score also showed that both social distal and social ultimate variables contributed to the model (Table 4). However, social distal variables (Table 4, Model 2; LLR $=254.07 ; \mathrm{DF}=8 ; p<.001$ ) contributed much more to the model than social ultimate variables (Table 4, Model 1; LLR $=22.03 ; \mathrm{DF}=5 ; p<.001$ ).

Adjusted longitudinal Poisson models (i.e., including both individual and social variables) led to similar

Table 3 Rate ratios $(95 \% \mathrm{Cls}$ ) for the longitudinal associations between selected individual distal and individual ultimate variables and multiple behavioral risk factors $(n=1135)$, National Longitudinal Survey of Children and Youth, 2000-2005

\begin{tabular}{|c|c|c|c|c|c|c|c|c|c|}
\hline & Rate ratio ${ }^{b} 95 \% \mathrm{Cl}^{c}$ & & & Rate ratio ${ }^{b} 95 \% \mathrm{Cl}^{c}$ & & & Rate ratio ${ }^{b} 95 \% \mathrm{Cl}^{c}$ & & \\
\hline & Model 1 & & & Model 2 & & & Model 3 & & \\
\hline & Individual characteristics & & & Individual characteristics & & & Individual characteristic & & \\
\hline & Ultimate & & & Distal & & & Ultimate & & \\
\hline & Sex & & & Self-esteem $^{f}$ & 0.97 & $0.97,0.98$ & Sex & & \\
\hline & Female & 1 & Referent & Academic performance & & & Female & 1 & Referent \\
\hline & Male & 1.01 & $0.96,1.06$ & Poor/very poor & 1 & Referent & Male & 1.00 & $0.95,1.05$ \\
\hline & Age, years ${ }^{d}$ & & & Average & 0.93 & $0.85,1.01$ & Age, years $^{\mathrm{d}}$ & & \\
\hline & 10 & 1 & Referent & Well & 0.88 & $0.80,0.96$ & 10 & 1 & Referent \\
\hline & 11 & 1.08 & $1.02,1.15$ & Very well & 0.88 & $0.79,0.97$ & 11 & 1.07 & $1.01,1.13$ \\
\hline & Anxiety $^{e}$ & 1.02 & $1.01,1.03$ & Time & & & Anxiety $^{e}$ & 1.01 & $1.00,1.02$ \\
\hline & Time & & & 1 (Cycle 4) & 1 & Referent & Distal & & \\
\hline & 1 (Cycle 4) & 1 & Referent & 2 (Cycle 5) & 1.08 & $1.03,1.14$ & Self-esteem $^{f}$ & 0.98 & $0.97,0.98$ \\
\hline & 2 (Cycle 5) & 1.11 & $1.06,1.17$ & 3 (Cycle 6) & 1.37 & $1.30,1.44$ & Academic performance & & \\
\hline & 3 (Cycle 6) & 1.43 & $1.35,1.50$ & Intercept & 3.38 & $3.00,3.81$ & Poor/very poor & 1 & Referent \\
\hline & Intercept & 1.89 & $1.78,2.01$ & & & & Average & 0.93 & $0.85,1.01$ \\
\hline & & & & & & & Well & 0.88 & $0.80,0.97$ \\
\hline & & & & & & & Very well & 0.88 & $0.79,0.98$ \\
\hline & & & & & & & Time & & \\
\hline & & & & & & & 1 (Cycle 4) & 1 & Referent \\
\hline & & & & & & & 2 (Cycle 5) & 1.09 & $1.03,1.14$ \\
\hline & & & & & & & 3 (Cycle 6) & 1.37 & $1.30,1.44$ \\
\hline & & & & & & & Intercept & 3.09 & $2.66,3.60$ \\
\hline$-2 \log L^{9}$ & 1335.42 & & & 1294.37 & & & 1285.03 & & \\
\hline Log $L$ ratio $^{h}$ & $35.90^{* * *}$ & & & $76.94^{* * *}$ & & & $86.28^{* * *}$ & & \\
\hline DF & 3 & & & 4 & & & 7 & & \\
\hline
\end{tabular}

$\mathrm{Cl}=$ confidence interval; DF = degrees of freedom.

${ }^{a}$ Multiple behavioral risk factor score was the dependent variable.

${ }^{b}$ Rate ratios from the multivariate longitudinal Poisson regression model with adjustment for all covariates in the corresponding model and time (cycles).

${ }^{c} \mathrm{Cls}$ were computed using bootstrap weights to account for the complex sampling design of the National Longitudinal Survey of Children and Youth.

${ }^{\mathrm{d}}$ Age at baseline (Cycle 4).

${ }^{e}$ Anxiety was assessed using a global score ranging from 0 to 14 , with higher scores indicating the presence of greater anxiety.

f Self-esteem was assessed using a global score ranging from 0 to 16 , with higher scores indicating positive self-esteem.

g-2 (log-likelihood) for the model containing each specific block of distal and/or ultimate variables. The -2 (log-likelihood) of the initial (intercept-only + time) model was 1371.31.

${ }^{\mathrm{h}}$ Log-likelihood ratio or change in -2 (log-likelihood) compared to the initial (intercept-only + time) model.

*** $p<.001$. 
Table 4 Rate ratios ( $95 \% \mathrm{Cls}$ ) for the longitudinal associations between selected social distal and social ultimate variables and multiple behavioral risk factors $(n=1135)$, National Longitudinal Survey of Children and Youth, 2000$2005^{a}$

\begin{tabular}{|c|c|c|c|c|c|c|c|c|c|}
\hline & Rate ratio ${ }^{b} 95 \% \mathrm{Cl}^{c}$ & & & Rate ratio ${ }^{b} 95 \% \mathrm{Cl}^{c}$ & & & Rate ratio ${ }^{b} 95 \% \mathrm{Cl}^{c}$ & & \\
\hline & Model 1 & & & Model 2 & & & Model 3 & & \\
\hline & Social characteristics & & & Social characteristics & & & Social characteristics & & \\
\hline & Ultimate & & & Distal & & & Ultimate & & \\
\hline & Family structure & & & PMK smoking status & & & Family structure & & \\
\hline & 2 parents & 1 & Referent & Nonsmoker & 1 & Referent & 2 parents & 1 & Referent \\
\hline & 1 parent & 1.07 & $0.98,1.17$ & Smoker & 1.10 & $1.05,1.15$ & 1 parent & 1.05 & $0.97,1.12$ \\
\hline & PMK Education & & & PMK drinking status & & & PMK Education & & \\
\hline & Low $(<12$ years of school) & 1 & Referent & Nondrinker & 1 & Referent & Low (< 12 years of school) & 1 & Referent \\
\hline & High ( $\geq 12$ years of school) & 0.94 & $0.88,1.01$ & Drinker & 1.01 & $0.97,1.06$ & High ( $\geq 12$ years of school) & 0.98 & $0.92,1.04$ \\
\hline & Annual household income & & & Parent-child relationship $^{d}$ & 0.99 & $0.99,1.00$ & Annual household income & & \\
\hline & $<$ CAN\$30,000 & 1 & Referent & Peer smoking & & & $<$ CAN\$30,000 & 1 & Referent \\
\hline & CAN\$30,000 -59,999 & 1.01 & $0.94,1.09$ & No peers & 1 & Referent & CAN\$30,000 -59,999 & 1.01 & $0.94,1.08$ \\
\hline & CAN\$60,000 -89,999 & 1.07 & $0.98,1.16$ & A few peers & 1.14 & $1.06,1.22$ & CAN\$60,000 -89,999 & 1.09 & $1.00,1.17$ \\
\hline & $\geq \operatorname{CAN\$ 90,000}$ & 1.03 & $0.93,1.13$ & Most/All peers & 1.41 & $1.27,1.56$ & $\geq$ CAN\$90,000 & 1.04 & $0.96,1.14$ \\
\hline & Time & & & Peer drinking & & & Distal & & \\
\hline & 1 (Cycle 4) & 1 & Referent & No peers & 1 & Referent & PMK smoking status & & \\
\hline & 2 (Cycle 5) & 1.10 & $1.05,1.16$ & A few peers & 1.13 & $1.06,1.21$ & Nonsmoker & 1 & Referent \\
\hline & 3 (Cycle 6) & 1.41 & $1.34,1.49$ & Most/All peers & 1.26 & $1.17,1.37$ & Smoker & 1.10 & $1.05,1.15$ \\
\hline & Intercept & 2.10 & $1.94,2.29$ & Peer-child relationship ${ }^{e}$ & 0.99 & $0.98,1.00$ & PMK drinking status & & \\
\hline & & & & Time & & & Nondrinker & 1 & Referent \\
\hline & & & & 1 (Cycle 4) & 1 & Referent & Drinker & 1.01 & $0.97,1.05$ \\
\hline & & & & 2 (Cycle 5) & 1.06 & $1.01,1.11$ & Parent-child relationship $^{d}$ & 0.99 & $0.99,1.00$ \\
\hline & & & & 3 (Cycle 6) & 1.16 & $1.09,1.24$ & Peer smoking & & \\
\hline & & & & Intercept & 2.75 & $2.45,3.08$ & No peers & 1 & Referent \\
\hline & & & & & & & A few peers & 1.14 & $1.06,1.22$ \\
\hline & & & & & & & Most/All peers & 1.41 & $1.27,1.57$ \\
\hline & & & & & & & Peer drinking & & \\
\hline & & & & & & & No peers & 1 & Referent \\
\hline & & & & & & & A few peers & 1.13 & $1.06,1.21$ \\
\hline & & & & & & & Most/All peers & 1.26 & $1.17,1.36$ \\
\hline & & & & & & & Peer-child relationship ${ }^{e}$ & 0.99 & $0.98,1.00$ \\
\hline & & & & & & & Time & & \\
\hline & & & & & & & 1 (Cycle 4) & 1 & Referent \\
\hline & & & & & & & 2 (Cycle 5) & 1.05 & $1.00,1.11$ \\
\hline & & & & & & & 3 (Cycle 6) & 1.15 & $1.08,1.23$ \\
\hline & & & & & & & Intercept & 2.71 & $2.39,3.07$ \\
\hline$-2 \log L^{f}$ & 1349.28 & & & 1117.23 & & & 1107.07 & & \\
\hline Log L ratio ${ }^{g}$ & $22.03^{* * *}$ & & & $254.07^{* * *}$ & & & $264.24^{* * *}$ & & \\
\hline DF & 5 & & & 8 & & & 13 & & \\
\hline
\end{tabular}

CAN = Canadian; $\mathrm{Cl}$ = confidence interval; DF = degrees of freedom; PMK = person most knowledgeable.

${ }^{\text {a }}$ Multiple behavioral risk factor score was the dependent variable.

${ }^{b}$ Rate ratios from the multivariate longitudinal Poisson regression model with adjustment for all covariates in the corresponding model and time (cycles).

c Cls were computed using bootstrap weights to account for the complex sampling design of the National Longitudinal Survey of Children and Youth.

${ }^{d}$ The parent-child relationship was assessed using a global score ranging from 0 to 28 , with higher scores indicating a better relationship between parents and child.

e Peer-child relationships were assessed using a global score ranging from 0 to 16 , with higher scores indicating a better relationship between the child and his/ her peers.

f -2 (log-likelihood) for the model containing each specific block of distal and/or ultimate variables. The -2 (log-likelihood) of the initial (intercept-only + time) model was 1371.31 .

${ }^{9}$ Log-likelihood ratio or change in -2 (log-likelihood) compared to the initial (intercept-only + time) model.

${ }^{* * *} p<.001$. 
results as in the models investigating the direct influence of individual distal/ultimate and social distal/ultimate variables. In particular, social distal variables (Table 5, Model 3, LLR $=187.86 ; \mathrm{DF}=8 ; p<.001)$, individual distal variables (Table 5 , Model 1 , LLR = 76.94; $\mathrm{DF}=4 ; p<.001)$, and individual ultimate variables (Table 5, Model 2, LLR $=9.34 ; \mathrm{DF}=3 ; p<.05$ ) significantly contributed to the rate of multiple risk factor score. Social ultimate variables (Table 5, Model 4, $\mathrm{LLR}=10.93 ; \mathrm{DF}=5 ; p=.05)$ contributed minimally to the overall rate of occurrence of multiple behavioral risk factors. Among the variables under investigation, PMK smoking $($ rate ratio $(R R)=1.11 ; 95 \% C I=1.05,1.16$ ), having reported that a few or most/all of one's peers drank alcohol (a few-RR $=1.12 ; 95 \% \mathrm{CI}=1.04,1.19$; most $/$ all-RR $=1.23 ; 95 \% \mathrm{CI}=1.14,1.34)$ or smoked cigarettes (a few- $\mathrm{RR}=1.14 ; 95 \% \mathrm{CI}=1.07,1.22$; most $/$ all-RR $=1.41 ; 95 \% \mathrm{CI}=1.28,1.55)$ were associated with an increased rate of multiple risk factor score (Table 5 , Model 4). Higher self-esteem ( $R R=0.98 ; 95 \% C I=0.98$, 0.99) was related to a decline in the rate of multiple risk factor score (Table 5, Model 4).

\section{Discussion}

This study assessed the longitudinal influence of selected conceptually-related individual and social variables on the rate of occurrence of multiple behavioral risk factors in a representative cohort of Canadian youth. Our results first indicate a $23 \%$ increase in the percentage of youth with 3 or more risk factors and a $20 \%$ decline in the percentage of youth with 0 risk factors across the follow-up period. As expected, both distal and ultimate variables contributed to the likelihood of the occurrence of multiple behavioral risk factors during follow-up. However, contrary to our expectation, the log-likelihood ratio statistic indicated that distal variables, particularly social distal factors, contributed more to the longitudinal Poisson model than ultimate variables. This finding is important because distal variables tend to be actually easier to modify through effective interventions compared to ultimate variables [39]. We are aware of no other study assessing the influence of blocks of distal or ultimate variables on the rate of occurrence of multiple behavioral risk factors in either youth or adults. Hence, it is difficult to compare results of this study with other relevant reports. Nevertheless, our results corroborate findings of a recent cross-sectional study, also based on the Theory of Triadic Influence, where friends' substance use, a social distal variable, was found to be associated with both alcohol use and cigarette smoking in two convenience samples of Russian and American high school students in grade 10. In contrast, depression, an individual ultimate variable, was not associated with either behavior in the same study [65].
Of the social distal variables considered in our study, caregiver smoking was linked to an $11 \%$ increase in the rate of multiple risk factor score among youth. Adverse parental health behaviors have been associated with unhealthy behaviors of their children in only two crosssectional studies of multiple behavioral risk factors for chronic diseases [25,27], as well as longitudinal studies of single risk factors including cigarette smoking [66] and obesity $[67,68]$. Two other social distal variables including having peers who smoked cigarettes and having peers who drank alcohol increased the likelihood of having multiple risk factors by up to $41 \%$ and $23 \%$, respectively. These findings are consistent with results of other observational studies where peer smoking [69] and peer drinking [70] were associated with the occurrence of single behavioral risk factors among adolescents. However, we are aware of no other longitudinal study investigating the potential association between peer unhealthy lifestyles and the rate of occurrence of multiple behavioral risk factors for chronic diseases among youth. Nevertheless, as suggested by several social bonding theories, parents and peers are perceived as role models, and are thought to affect youth health behaviors by shaping perceived social norms to adopt or maintain health behaviors [39]. Moreover, these results concord well with findings of existing intervention literature where effective interventions have tended to focus on social distal factors (such as parental and peer behaviors and parental involvement) for preventing risk factors such as cigarette smoking, unhealthy diet consumption, and obesity [71,72]. Hence, these findings suggest the importance of interventions in the child's immediate social environment to support multiple-behavior change.

Among the individual distal variables studied, higher self-esteem was associated with a decline in the rate of multiple risk factor score among youth. This finding is concordant with results of a longitudinal study where lower self-esteem was linked to single health-compromising behaviors including cigarette smoking, alcohol use and problem behavior among adolescents aged 15 years [73]. It has been suggested that individuals with stronger self-esteem tend to place greater value on selfdetermination and possess a strong will to modify, regulate or restrain their health behaviors [39].

The social ultimate variables considered in this study (i.e., parental education, household income and family structure) contributed minimally to the overall rate of multiple risk factor score. The evidence from the literature regarding the association of socioeconomic status and multiple behavioral risk factors for chronic diseases has been mixed. For example, in a recent cross-sectional study, family structure and education, but not income, were associated with multiple chronic disease behavioral 
Table 5 Adjusted rate ratios $(95 \% \mathrm{Cls})$ for the longitudinal associations between selected individual/social distal and ultimate variables and multiple behavioral risk factors $(n=1135)$, National Longitudinal Survey of Children and Youth, 2000-2005

\begin{tabular}{|c|c|c|c|c|c|c|c|c|c|c|c|}
\hline \multicolumn{3}{|c|}{ Rate ratio ${ }^{b} 95 \% \mathrm{Cl}^{\mathrm{c}}$} & \multicolumn{3}{|c|}{ Rate ratio ${ }^{\mathrm{b}} 95 \% \mathrm{Cl}^{\mathrm{c}}$} & \multicolumn{3}{|c|}{ Rate ratio ${ }^{\mathrm{b}} 95 \% \mathrm{Cl}^{\mathrm{c}}$} & \multicolumn{3}{|c|}{ Rate ratio ${ }^{\mathrm{b}} 95 \% \mathrm{Cl}^{\mathrm{c}}$} \\
\hline \multicolumn{3}{|l|}{ Model 1} & \multicolumn{3}{|l|}{ Model 2} & \multicolumn{3}{|l|}{ Model 3} & \multicolumn{3}{|l|}{ Model 4} \\
\hline \multicolumn{3}{|l|}{$\begin{array}{l}\text { Individual } \\
\text { characteristics }\end{array}$} & \multicolumn{3}{|l|}{$\begin{array}{l}\text { Individual } \\
\text { characteristics }\end{array}$} & \multicolumn{3}{|l|}{$\begin{array}{l}\text { Individual } \\
\text { characteristics }\end{array}$} & \multicolumn{3}{|l|}{$\begin{array}{l}\text { Individual } \\
\text { characteristics }\end{array}$} \\
\hline \multicolumn{3}{|l|}{ Distal } & \multicolumn{3}{|l|}{ Distal } & \multicolumn{3}{|l|}{ Distal } & \multicolumn{3}{|l|}{ Distal } \\
\hline Self-esteem $^{d}$ & 0.97 & $\begin{array}{l}0.97 \\
0.98\end{array}$ & Self-esteem $^{d}$ & 0.98 & $\begin{array}{l}0.97 \\
0.98\end{array}$ & Self-esteem $^{d}$ & 0.98 & $\begin{array}{l}0.98 \\
0.99\end{array}$ & Self-esteem $^{d}$ & 0.98 & $\begin{array}{l}0.98 \\
0.99\end{array}$ \\
\hline \multicolumn{3}{|l|}{$\begin{array}{l}\text { Academic } \\
\text { performance }\end{array}$} & \multicolumn{3}{|l|}{$\begin{array}{l}\text { Academic } \\
\text { performance }\end{array}$} & \multicolumn{3}{|l|}{$\begin{array}{l}\text { Academic } \\
\text { performance }\end{array}$} & \multicolumn{3}{|l|}{$\begin{array}{l}\text { Academic } \\
\text { performance }\end{array}$} \\
\hline $\begin{array}{l}\text { Poor/very } \\
\text { poor }\end{array}$ & 1 & Referent & $\begin{array}{l}\text { Poor/very } \\
\text { poor }\end{array}$ & 1 & Referent & $\begin{array}{l}\text { Poor/very } \\
\text { poor }\end{array}$ & 1 & Referent & $\begin{array}{l}\text { Poor/very } \\
\text { poor }\end{array}$ & 1 & Referent \\
\hline Average & 0.93 & $\begin{array}{l}0.85 \\
1.01 \\
\end{array}$ & Average & 0.93 & $\begin{array}{l}0.85 \\
1.01 \\
\end{array}$ & Average & 0.98 & $\begin{array}{l}0.88 \\
1.09 \\
\end{array}$ & Average & 0.98 & $\begin{array}{l}0.88 \\
1.09 \\
\end{array}$ \\
\hline Well & 0.88 & $\begin{array}{l}0.80 \\
0.96 \\
\end{array}$ & Well & 0.88 & $\begin{array}{l}0.80, \\
0.97 \\
\end{array}$ & Well & 0.94 & $\begin{array}{l}0.84, \\
1.05 \\
\end{array}$ & Well & 0.94 & $\begin{array}{l}0.84 \\
1.04 \\
\end{array}$ \\
\hline Very well & 0.88 & $\begin{array}{l}0.79 \\
0.97\end{array}$ & Very well & 0.88 & $\begin{array}{l}0.79 \\
0.98\end{array}$ & Very well & 0.96 & $\begin{array}{l}0.86 \\
1.08\end{array}$ & Very well & 0.96 & $\begin{array}{l}0.85 \\
1.08\end{array}$ \\
\hline \multicolumn{3}{|l|}{ Time } & \multicolumn{3}{|l|}{ Ultimate } & \multicolumn{3}{|l|}{ Ultimate } & \multicolumn{3}{|l|}{ Ultimate } \\
\hline 1 (Cycle 4) & 1 & Referent & \multicolumn{3}{|l|}{ Sex } & \multicolumn{3}{|l|}{ Sex } & \multicolumn{3}{|l|}{ Sex } \\
\hline 2 (Cycle 5) & 1.08 & $\begin{array}{l}1.03 \\
1.14 \\
\end{array}$ & Female & 1 & Referent & Female & 1 & Referent & Female & 1 & Referent \\
\hline 3 (Cycle 6) & 1.37 & $\begin{array}{l}1.30 \\
1.44\end{array}$ & Male & 1.00 & $\begin{array}{l}0.95 \\
1.05\end{array}$ & Male & 1.01 & $\begin{array}{l}0.97 \\
1.05\end{array}$ & Male & 1.01 & $\begin{array}{l}0.97 \\
1.05\end{array}$ \\
\hline Intercept & 3.38 & $\begin{array}{l}3.00, \\
3.81\end{array}$ & Age, years ${ }^{\mathrm{e}}$ & & & Age, years ${ }^{\mathrm{e}}$ & & & Age, years ${ }^{\mathrm{e}}$ & & \\
\hline & & & 10 & 1 & Referent & 10 & 1 & Referent & 10 & 1 & Referent \\
\hline & & & 11 & 1.07 & $\begin{array}{l}1.01 \\
1.13\end{array}$ & 11 & 1.01 & $\begin{array}{l}0.96 \\
1.06\end{array}$ & 11 & 1.01 & $\begin{array}{l}0.96 \\
1.06\end{array}$ \\
\hline & & & Anxiety $^{f}$ & 1.01 & $\begin{array}{l}1.00 \\
1.02\end{array}$ & Anxiety $^{f}$ & 1.00 & $\begin{array}{l}0.99 \\
1.01\end{array}$ & Anxiety $^{f}$ & 1.01 & $\begin{array}{l}1.00 \\
1.01\end{array}$ \\
\hline & & & Time & & & $\begin{array}{l}\text { Social } \\
\text { characteristics }\end{array}$ & & & $\begin{array}{l}\text { Social } \\
\text { characteristics }\end{array}$ & & \\
\hline & & & 1 (Cycle 4) & 1 & Referent & Distal & & & Distal & & \\
\hline & & & 2 (Cycle 5) & 1.09 & $\begin{array}{l}1.03 \\
1.14\end{array}$ & $\begin{array}{l}\text { PMK smoking } \\
\text { status }\end{array}$ & & & $\begin{array}{l}\text { PMK smoking } \\
\text { status }\end{array}$ & & \\
\hline & & & 3 (Cycle 6) & 1.37 & $\begin{array}{l}1.30 \\
1.44\end{array}$ & Nonsmoker & 1 & Referent & Nonsmoker & 1 & Referent \\
\hline & & & Intercept & 3.09 & $\begin{array}{l}2.66 \\
3.60\end{array}$ & Smoker & 1.10 & $\begin{array}{l}1.05 \\
1.16\end{array}$ & Smoker & 1.11 & $\begin{array}{l}1.05 \\
1.16\end{array}$ \\
\hline & & & & & & $\begin{array}{l}\text { PMK drinking } \\
\text { status }\end{array}$ & & & $\begin{array}{l}\text { PMK drinking } \\
\text { status }\end{array}$ & & \\
\hline & & & & & & Nondrinker & 1 & Referent & Nondrinker & 1 & Referent \\
\hline & & & & & & Drinker & 1.01 & $\begin{array}{l}0.97 \\
1.06 \\
\end{array}$ & Drinker & 1.01 & $\begin{array}{l}0.97 \\
1.05\end{array}$ \\
\hline & & & & & & $\begin{array}{l}\text { Parent-child } \\
\text { relationship }\end{array}$ & 1.00 & $\begin{array}{l}0.99 \\
1.00\end{array}$ & $\begin{array}{l}\text { Parent-child } \\
\text { relationship }\end{array}$ & 1.00 & $\begin{array}{l}0.99 \\
1.00\end{array}$ \\
\hline & & & & & & Peer smoking & & & Peer smoking & & \\
\hline & & & & & & No peers & 1 & Referent & No peers & 1 & Referent \\
\hline & & & & & & A few peers & 1.13 & $\begin{array}{l}1.06 \\
1.21\end{array}$ & A few peers & 1.14 & $\begin{array}{l}1.07 \\
1.22\end{array}$ \\
\hline & & & & & & Most/All peers & 1.40 & $\begin{array}{l}1.27 \\
1.54 \\
\end{array}$ & Most/All peers & 1.41 & $\begin{array}{l}1.28 \\
1.55\end{array}$ \\
\hline & & & & & & Peer drinking & & & Peer drinking & & \\
\hline & & & & & & No peers & 1 & Referent & No peers & 1 & Referent \\
\hline
\end{tabular}


Table 5 Adjusted rate ratios (95\% Cls) for the longitudinal associations between selected individual/social distal and ultimate variables and multiple behavioral risk factors $(n=1135)$, National Longitudinal Survey of Children and Youth, 2000-2005 ${ }^{\text {a }}$ (Continued)

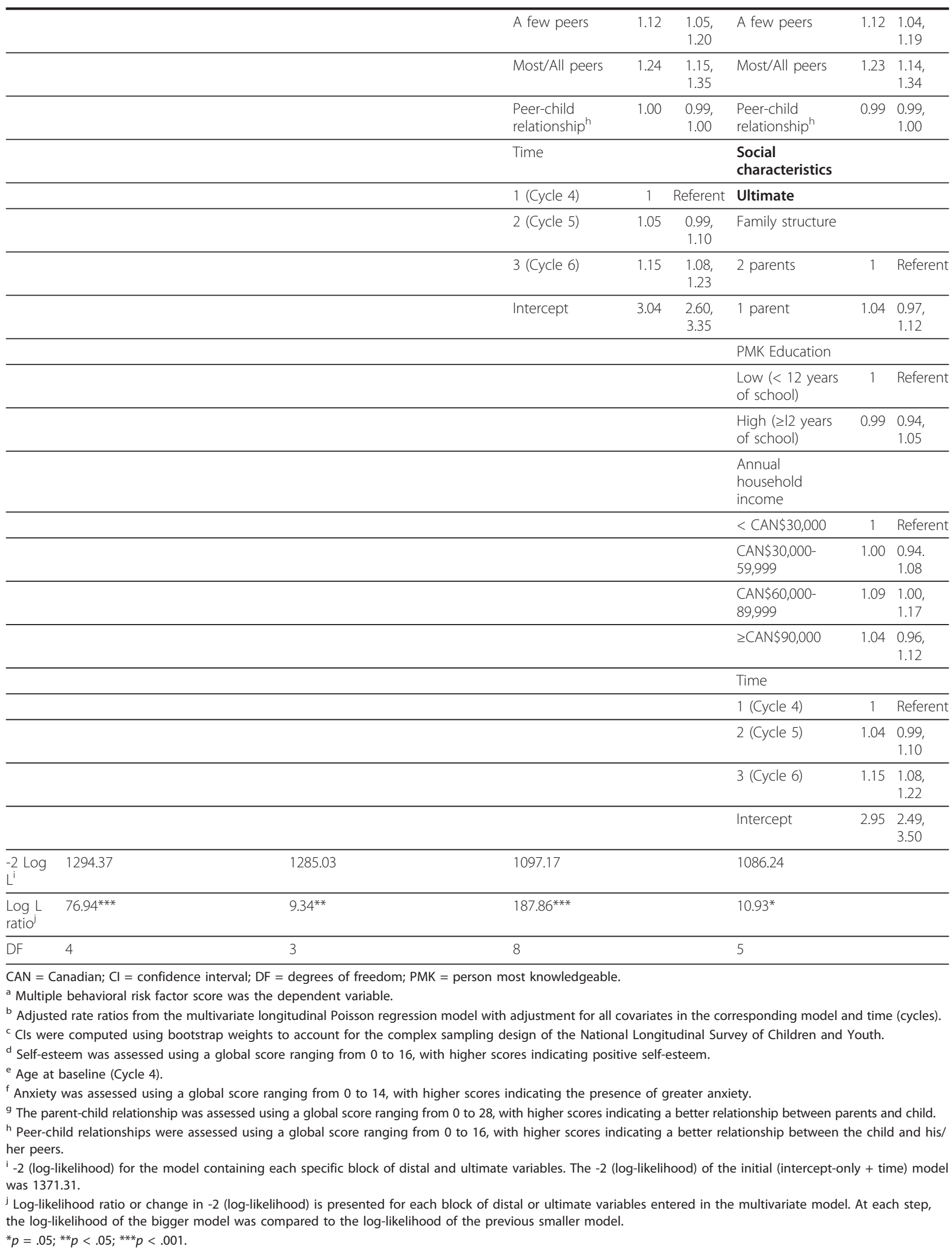


risk factors among Canadian youth aged 10-15 years [27]. An Australian study found a cross-sectional association between family income and the co-occurrence of behavioral risk factors among adolescents aged 14 years [21], while two American cross-sectional studies did not find an association between parental level of education and the presence of multiple behavioral risk factors in children and adolescents aged 11 to 15 years $[25,26]$. These divergent findings may be partly attributed to the use of different definitions for parental education and household income across these cross-sectional studies. Hence, there is a need for additional research on the association of family socioeconomic status and the occurrence of multiple chronic disease behavioral risk factors among youth, particularly using longitudinal designs.

This study comprised some limitations. First, adopting a theory-based approach has its drawbacks as it often relates poorly to the real world. For example, the ultimate tier of influence may comprise additional factors (such as factors related to the broader socioeconomic context of youth) not included in the study. Also, the mechanisms by which distal and ultimate factors influence multiple behaviors may be more complex than what is depicted in the conceptual framework of the study. Nevertheless, the Theory of Triadic Influence does recognize that there are possible interstream pathways between different levels of influence. For example, the child's age (an individual ultimate variable) might have its primary influence on the child's sense of self (an individual distal variable) but it might also, to a lesser degree, influence how well the child bonds with others (a social distal variable) [39].

Second, some selection bias may have occurred due to loss to follow-up or the exclusion of subjects because of incomplete data. In particular, the sample may have been somewhat selected towards youth from more affluent and healthy families. Since single and multiple behavioral risk factors tend to be more prevalent among youth of low socioeconomic status [23], the observed associations herein may be even stronger in reality because of the limited inclusion of youth from less affluent families. Also, although our final multivariate model adjusted for all covariates, it remains possible that additional unaccounted factors explain our findings.

Health behaviors were self-reported in the NLSCY and thus subject to recall and social desirability biases. Moreover, the measure of body mass index was based on parent-reported height and weight for children aged 10-11 years, and self-reported height and weight for adolescents aged 12 years or over in the NLSCY. It has been suggested that when parents report their children's height and weight, overweight and obesity may be overestimated, mainly because parents tend to underestimate their children's height [74]. In contrast, self-reported height and weight tend to yield slightly lower estimates of body mass index compared to objective measures [74].

Lastly, the five behavioral risk factors under study were summed to create a multiple risk factor score. To construct this score, each behavior was dichotomized, the practice of which necessarily entails some loss of information. However, since behaviors under study were measured on different scales, dichotomization according to national/international cutoff points was judged appropriate. Also, some authors have questioned the use of additive indices where risk factors are attributed equal weights $[75,76]$. In contrast, other experts have shown that use of equally weighted risk factor indices results in the identification of very similar at risk populations than those identified by unequally weighted risk factor indices $[77,78]$.

Despite these limitations, this study had several important strengths including its use of a nationally representative sample of youth, the use of an integrative theoretical framework to guide the study of determinants of multiple behavioral risk factors, and its longitudinal design.

\section{Conclusions}

This study contributed new knowledge about determinants of multiple chronic disease behavioral risk factors among youth. In particular, this longitudinal investigation showed that individual distal and social distal variables exerted a stronger influence on the rate of cooccurrence of behavioral risk factors among youth, compared to individual/social ultimate variables. Specifically, parental and peer unhealthy lifestyles were associated with an elevated rate of multiple risk factor score. Youth with stronger sense of self over time were less likely to have multiple behavioral risk factors. These results support the use of distal variables as potential targets in public health interventions aiming to curb the increased rate of occurrence of multiple behavioral risk factors among youth. Further research is needed to evaluate the influence of ultimate variables, often considered the root causes of behaviors and hard to modify [39], on multiple behavioral risk factors among youth.

\section{Acknowledgements}

This study was supported by grant NRF84288 from the Canadian Institutes of Health Research (CIHR). AA was supported by a Doctoral Research Award from the CIHR Institute of Population and Public Health - Public Health Agency of Canada and a scholarship from the Transdisciplinary Research Training Program on Interventions in Public Health: Promotion, Prevention and Public Policy (4P) of the CIHR and the Quebec Population Health Research Network. GP holds a CIHR Chair in Applied Public Health Research. We would like to thank the National Public Health Institute of Quebec for its material support and the Quebec Inter-University Centre for Social Statistics for its analytical advice and support. All analyses were performed based on 
data obtained by permission from Statistics Canada. The opinions expressed by the authors are strictly their own and do not represent the views of Statistics Canada.

\section{Author details}

${ }^{1}$ Department of Biostatistics and Epidemiology, College of Public Health, East Tennessee State University, Johnson City, Tennessee, USA. ${ }^{2}$ Department of Epidemiology, Biostatistics and Occupational Health, Faculty of Medicine, McGill University, Montreal, Quebec, Canada. ${ }^{3}$ Research Institute of the McGill University Health Centre, Montreal, Quebec, Canada.

\section{Authors' contributions}

AA designed the study, conducted the analyses, interpreted the data and wrote the manuscript. GP contributed to data interpretation, provided comments on and reviewed the manuscript critically for important intellectual content and quality. Both authors have read and approved the final manuscript.

\section{Competing interests}

The authors declare that they have no competing interests.

Received: 29 June 2011 Accepted: 22 March 2012

Published: 22 March 2012

\section{References}

1. World Health Organization: Preventing chronic diseases: a vital statement Geneva, Switzerland: Department of Chronic Diseases and Health Promotion, World Health Organization; 2005.

2. Mokdad AH, Marks JS, Stroup DF, Gerberding JL: Actual causes of death in the United States, 2000. JAMA 2004, 291(10):1238-1245.

3. Yusuf S, Hawken S, Ounpuu S, Dans T, Avezum A, Lanas F, McQueen M, Budaj A, Pais P, Varigos J, Lisheng L: Effect of potentially modifiable risk factors associated with myocardial infarction in 52 countries (the INTERHEART study): case-control study. Lancet 2004, 364(9438):937-952.

4. Danaei G, Vander Hoorn S, Lopez AD, Murray CJ, Ezzati M: Causes of cancer in the world: comparative risk assessment of nine behavioural and environmental risk factors. Lancet 2005, 366(9499):1784-1793.

5. Milton B, Woods SE, Dugdill L, Porcellato L, Springett RJ: Starting young? Children's experiences of trying smoking during pre-adolescence. Health Educ Res 2008, 23(2):298-309.

6. Dube SR, Miller JW, Brown DW, Giles WH, Felitti VJ, Dong M, Anda RF: Adverse childhood experiences and the association with ever using alcohol and initiating alcohol use during adolescence. J Adolesc Health 2006, 38(4):444e1-444.e10.

7. Basterfield L, Adamson AJ, Frary JK, Parkinson KN, Pearce MS, Reilly J: Longitudinal study of physical activity and sedentary behavior in children. Pediatrics 2011, 127(1):e24-e30.

8. Sisson SB, Church TS, Martin CK, Tudor-Locke C, Smith SR, Bouchard C, Earnest CP, Rankinen T, Newton RL, Katzmarzyk PT: Profiles of sedentary behavior in children and adolescents: the US National Health and Nutrition Examination Survey, 2001-2006. Int J Pediatr Obes 2009, 4(4):353-359.

9. Herman KM, Craig CL, Gauvin L, Katzmarzyk PT: Tracking of obesity and physical activity from childhood to adulthood: the Physical Activity Longitudinal Study. Int J Pediatr Obes 2009, 4(4):281-288.

10. Kasa-Vubu JZ, Lee CC, Rosenthal A, Singer K, Halter JB: Cardiovascular fitness and exercise as determinants of insulin resistance in postpubertal adolescent females. J Clin Endocrinol Metab 2005, 90(2):849-854.

11. Reilly JJ, Kelly J: Long-term impact of overweight and obesity in childhood and adolescence on morbidity and premature mortality in adulthood: systematic review. Int J Obes (Lond) 2011, 35(7):891-898.

12. Tremblay MS, Willms JD: Is the Canadian childhood obesity epidemic related to physical inactivity? Int J Obes Relat Metab Disord 2003, 27(9):1100-1105.

13. Leary SD, Ness AR, Smith GD, Mattocks C, Deere K, Blair SN, Riddoch C: Physical activity and blood pressure in childhood: findings from a population-based study. Hypertension 2008, 51(1):92-98.

14. Strasburger VC: Children, adolescents, obesity, and the media. Pediatrics 2011, 128(1):201-208.
15. Mathers M, Toumbourou JW, Catalano RF, Williams J, Patton GC: Consequences of youth tobacco use: a review of prospective behavioural studies. Addiction 2006, 101(7):948-958.

16. World Health Organization: Health effects of smoking among young people. [http://www.who.int/tobacco/research/youth/health_effects/en/]

17. Centers for Disease Control and Prevention (CDC): Quick Stats: Underage Drinking. [http://www.cdc.gov/alcohol/fact-sheets/underage-drinking.htm]

18. Reilly JJ, Methven E, McDowell ZC, Hacking B, Alexander D, Stewart L, Kelnar CJ: Health consequences of obesity. Arch Dis Child 2003, 88(9):748-752.

19. Ho TF: Cardiovascular risks associated with obesity in children and adolescents. Ann Acad Med Singapore 2009, 38(1):48-49.

20. Driskell MM, Dyment S, Mauriello L, Castle P, Sherman K: Relationships among multiple behaviors for childhood and adolescent obesity prevention. Prev Med 2008, 46(3):209-215.

21. Lawlor DA, O'Callaghan MJ, Mamun AA, Williams GM, Bor W, Najman JM: Socioeconomic position, cognitive function, and clustering of cardiovascular risk factors in adolescence: findings from the Mater University Study of Pregnancy and its outcomes. Psychosom Med 2005, 67(6):862-868

22. Plotnikoff RC, Karunamuni N, Spence JC, Storey K, Forbes L, Raine K, Cameron Wild T, McCargar L: Chronic disease-related lifestyle risk factors in a sample of Canadian adolescents. J Adolesc Health 2009, 44(6):606-609.

23. Alamian A, Paradis G: Clustering of chronic disease behavioral risk factors in Canadian children and adolescents. Prev Med 2009, 48(5):493-499.

24. Meng L, Maskarinec G, Lee J, Kolonel LN: Lifestyle factors and chronic diseases: application of a composite risk index. Prev Med 1999, 29(4):296-304

25. Sanchez A, Norman GJ, Sallis JF, Calfas KJ, Cella J, Patrick K: Patterns and correlates of physical activity and nutrition behaviors in adolescents. Am J Prev Med 2007, 32(2):124-130.

26. Mistry R, McCarthy WJ, Yancey AK, Lu Y, Patel M: Resilience and patterns of health risk behaviors in California adolescents. Prev Med 2009, 48(3):291-297.

27. Alamian A, Paradis G: Correlates of multiple chronic disease behavioral risk factors in Canadian children and adolescents. Am J Epidemiol 2009, 170(10):1279-1289.

28. Pronk NP, Anderson LH, Crain AL, Martinson BC, O'Connor PJ, Sherwood NE, Whitebird RR: Meeting recommendations for multiple healthy lifestyle factors. Prevalence, clustering, and predictors among adolescent, adult, and senior health plan members. Am J Prev Med 2004, 27(Suppl 2):25-33.

29. Noar SM, Chabot M, Zimmerman RS: Applying health behavior theory to multiple behavior change: considerations and approaches. Prev Med 2008, 46(3):275-280.

30. Li FX, Robson PJ, Chen Y, Oiu Z, Lo Siou G, Bryant HE: Prevalence, trend, and sociodemographic association of five modifiable lifestyle risk factors for cancer in Alberta and Canada. Cancer Causes Control 2009, 20(3):395-407.

31. Becker MH: The Health Belief Model and Personal Health Behavior. Health Educ Monogr 1974, 2:324-473.

32. Ajzen I, Fishbein M: Understanding attitudes and predicting social behavior Englewood Cliffs, NJ: Prentice Hall; 1980

33. Ajzen I: The Theory of Planned Behavior. Organ Behav Hum Decis Process 1991, 50(2):179-211.

34. Petraitis J, Flay BR, Miller TQ: Reviewing theories of adolescent substance use: organizing pieces in the puzzle. Psychol Bull 1995, 117(1):67-86.

35. Flay BR: Positive youth development requires comprehensive health promotion programs. Am J Health Behav 2002, 26(6):407-424.

36. Bandura A: Social Foundations of Thought and Action: A Social Cognitive Theory Englewood Cliffs, NJ: Prentice Hall; 1986.

37. Jessor R: Risk behavior in adolescence: a psychosocial framework for understanding and action. J Adolesc Health 1991, 12(8):597-605.

38. Bronfenbrenner $\mathrm{U}$ : Toward an experimental ecology of human development. Am Psychol 1977, 32(7):513-531.

39. Flay BR, Petraitis J: The theory of triadic influence: A new theory of health behavior with implications for preventive interventions. In Advances in Medical Sociology, Volume N: A reconsideration of models of health behavior change. Edited by: Albrecht GL. Greenwich, CT: JAI Press; 1994:19-44.

40. Statistics Canada and Human Resources Development Canada: National Longitudinal Survey of Children and Youth: Microdata User Guide, Cycle 6 
(September 2004 to June 2005) Ottawa, Ontario, Canada: Statistics Canada; 2006.

41. Wold B, Aaro LE, Smith C: Health Behaviour in School-aged Children: a WHO Cross-National Study, Research Protocol for the 1993-1994 Survey Bergen, Norway: University of Bergen; 1993.

42. Public Health Agency of Canada and Canadian Society for Exercise Physiology: Canada's Physical Activity Guides for Children and Youth Ottawa, Ontario, Canada: Public Health Agency of Canada; 2002.

43. Leger LA, Lambert J: A maximal multistage $20-\mathrm{m}$ shuttle run test to predict VO2 max. Eur J Appl Physiol Occup Physiol 1982, 49(1):1-12.

44. Booth ML, Okely AD, Chey T, Bauman A: The reliability and validity of the physical activity questions in the WHO health behaviour in schoolchildren (HBSC) survey: a population study. Br J Sports Med 2001, 35(4):263-267.

45. Committee on Public Education: American Academy of Pediatrics, American Academy of Pediatrics: children, adolescents, and television. Pediatrics 2001, 107(2):423-426.

46. Vereecken CA, Todd J, Roberts C, Mulvihill C, Maes L: Television viewing behaviour and associations with food habits in different countries. Public Health Nutr 2006, 9(2):244-250.

47. Pierce JP, Gilpin E: How long will today's new adolescent smoker be addicted to cigarettes? Am J Public Health 1996, 86(2):253-256.

48. O'Loughlin J, Renaud L, Paradis G, Meshefedjian G, Zhou X: Prevalence and correlates of early smoking among elementary schoolchildren in multiethnic, low-income inner-city neighborhoods. Ann Epidemiol 1998, 8(5):308-318

49. Health Canada: Youth Smoking Survey: Terminology. [http://www.hc-sc.gc ca/hc-ps/tobac-tabac/research-recherche/stat/survey-sondage_term-eng. php].

50. Statistics Canada and Human Resources Development Canada: National Longitudinal Survey of Children and Youth: Microdata User Guide, Cycle 4 (September 2000 to May 2001) Ottawa, Ontario, Canada: Statistics Canada; 2003.

51. DeWit DJ, Adlaf EM, Offord DR, Ogborne AC: Age at first alcohol use: a risk factor for the development of alcohol disorders. Am J Psychiatry 2000, 157(5):745-750

52. Warner LA, White HR: Longitudinal effects of age at onset and first drinking situations on problem drinking. Subst Use Misuse 2003, 38(14):1983-2016.

53. Pica L: Use of alcohol and drugs [in French]. In Quebec Survey on Use of Tobacco, Alcohol, Drug and Gambling in High School Students, 2004. Edited by: Dubé G. Quebec City, Quebec, Canada: Institut de la statistique du Québec; 2005:95-130

54. Cole TJ, Bellizzi MC, Flegal KM, Dietz WH: Establishing a standard definition for child overweight and obesity worldwide: international survey. BMJ 2000, 320(7244):1240-1243.

55. Statistics Canada: Ontario Child Health Study: Microdata user guide Ottawa, Ontario, Canada: Statistics Canada; 1987.

56. Marsh HW, O'Neil R: Self-Description Questionnaire III: The Construct Validity of Multidimensional Self-Concept Ratings by Late Adolescents. J Educ Meas 1984, 21(2):153-174.

57. Gilman R, Laughlin JE, Huebner ES: Validation of the Self-Description Questionnaire-II with an American Sample. Sch Psychol Int 1999, 2(3):300-307.

58. Kraywinkel K, Heidrich J, Heuschmann PU, Wagner M, Berger K: Stroke risk perception among participants of a stroke awareness campaign. BMC Public Health 2007, 7:e39.

59. Emerson E, Einfeld S, Stancliffe RJ: Predictors of the persistence of conduct difficulties in children with cognitive delay. J Child Psychol Psychiatry 2011, 52(11):1184-1194

60. Ross DP, Roberts P: Does family income affect the healthy development of children? Perception 1997, 21(1) [http://www.ccsd.ca/perception/211/ p211fi.htm].

61. Ding J, Eigenbrodt ML, Mosley TH Jr, Hutchinson RG, Folsom AR, Harris TB, Nieto FJ: Alcohol intake and cerebral abnormalities on magnetic resonance imaging in a community-based population of middle-aged adults: the Atherosclerosis Risk in Communities (ARIC) study. Stroke 2004 35(1):16-21.

62. Fisher RA, Yates F: Statistical Tables for Biological, Agricultural and Medical Research London, UK: Oliver and Boyd; 1938.
63. Zeger SL, Liang KY: Longitudinal data analysis for discrete and continuous outcomes. Biometrics 1986, 42(1):121-130.

64. Twisk JWR: Applied Longitudinal Data Analysis for Epidemiology: A Practical Guide Cambridge, UK: Cambridge University Press; 2006.

65. Gunning M, Sussman S, Rohrbach LA, Kniazev V, Masagutov R: Concurrent predictors of cigarette and alcohol use among U.S. and Russian adolescents. J Drug Educ 2009, 39(4):385-400.

66. Brook JS, Pahl K, Ning Y: Peer and parental influences on longitudinal trajectories of smoking among African Americans and Puerto Ricans. Nicotine Tob Res 2006, 8(5):639-651.

67. Burke $V$, Beilin LJ, Dunbar D: Family lifestyle and parental body mass index as predictors of body mass index in Australian children: a longitudinal study. Int J Obes Relat Metab Disord 2001, 25(2):147-157.

68. Valerio G, D'Amico O, Adinolfi M, Munciguerra A, D'Amico R, Franzese A: Determinants of weight gain in children from 7 to 10 years. Nutr Metab Cardiovasc Dis 2006, 16(4):272-278.

69. Ali MM, Dwyer DS: Estimating peer effects in adolescent smoking behavior: a longitudinal analysis. J Adolesc Health 2009, 45(4):402-408.

70. Van Der Vorst H, Vermulst AA, Meeus WH, Dekovic M, Engels RC: Identification and prediction of drinking trajectories in early and midadolescence. J Clin Child Adolesc Psychol 2009, 38(3):329-341.

71. Thomas RE, Baker P, Lorenzetti D: Family-based programmes for preventing smoking by children and adolescents. Cochrane Database Syst Rev 2007, , 1: CD004493.

72. Birch LL, Ventura AK: Preventing childhood obesity: what works? Int J Obes (Lond) 2009, 33(Suppl 1):74-81

73. McGee R, Williams S: Does low self-esteem predict health compromising behaviours among adolescents? J Adolesc 2000, 23(5):569-582.

74. Shields M: Overweight and obesity among children and youth. Health Rep 2006, 17(3):27-42.

75. Slater $\mathrm{CH}$, Linder $\mathrm{SH}$ : A reassessment of the additive scoring of health practices. Med Care 1988, 26(12):1216-1227.

76. Dean K, Salem N: Detecting measurement confounding in epidemiological research: construct validity in scaling risk behaviours: based on a population sample in Minnesota, USA. J Epidemiol Community Health 1998, 52(3):195-199.

77. Piacentini JC, Cohen P, Cohen J: Combining discrepant diagnostic information from multiple sources: are complex algorithms better than simple ones? J Abnorm Child Psychol 1992, 20(1):51-63.

78. Miller $Y$, Bauman A: Development of a chronic disease risk factor index and identifying population subgroups at risk using New South Wales Population Health Survey 2002 data. N S W Public Health Bull 2005, 16(910):141-147.

Pre-publication history

The pre-publication history for this paper can be accessed here: http://www.biomedcentral.com/1471-2458/12/224/prepub

doi:10.1186/1471-2458-12-224

Cite this article as: Alamian and Paradis: Individual and social determinants of multiple chronic disease behavioral risk factors among youth. BMC Public Health 2012 12:224

\section{Submit your next manuscript to BioMed Central and take full advantage of:}

- Convenient online submission

- Thorough peer review

- No space constraints or color figure charges

- Immediate publication on acceptance

- Inclusion in PubMed, CAS, Scopus and Google Scholar

- Research which is freely available for redistribution

Submit your manuscript at www.biomedcentral.com/submit
C Biomed Central 